\title{
AVALIAÇÃo DE MOdELOS DE PREVISÃo DE RUPTURA DE REDE DE ABASTECIMENTO DE ÁGUA
}

\section{Rinaldo Giovani T. Filho*, André Luís S. S. Martim. .}

\section{Resumo}

Este projeto de pesquisa pretende estudar sobre os modelos de previsão de substituição de rede e com dados de uma rede real de abastecimento de água, localizado no Município de São José dos Campos, Estado de São Paulo, avaliar a viabilidade de aplicação de um desses modelos. A partir das características reais da rede estudada inseridos no modelo matemático, os resultados obtidos com o modelo, serão avaliados de forma comparativa, com os dados reais de ruptura das redes de abastecimento obtidas no histórico de ocorrências.

\section{Palavras-chave:}

Ruptura das tubulações; modelos de previsão

\section{Introdução}

Devido aos altos custos econômicos, ambientais e sociais resultantes de rompimentos de tubulação em sistemas de distribuição de água, o desenvolvimento de um modelo de previsão confiável e preciso para avaliar a suscetibilidade de um tubo à falha é de suma importância. FARMANI, R. ; KAKOUDAKIS, K. et al.(2017).

Dentre os modelos de previsão de substituição de redes, o proposto por DALFRE e KURITA (2008) utiliza uma adaptação dos modelos de previsão de manutenção em redes de abastecimento existentes e utiliza dados reais de uma rede de abastecimento em sua modelagem, compreendendo um modelo físico mecânico para analisar as cargas impostas sobre a tubulação de PVC e às resistências estruturais da tubulação, com a finalidade de prever a ruptura.

O presente trabalho irá avaliar as rupturas das tubulações, especificamente as redes de distribuição, através de um modelo matemático de previsão de ruptura de redes, e de dados reais de operadoras de sistemas de distribuição.

\section{Resultados e Discussão}

A companhia de Saneamento Básico do estado de São Paulo disponibilizou dados de ocorrências de falhas nos SAA de São José dos Campos do ano de 2017/2018. Dividimos as ruas em trechos como pode ser visto na tabela 1.

Tabela 1. Vazamentos ocorridos por trecho no ano de 2017/2018 no município de São José dos Campos.

\begin{tabular}{|l|r|r|}
\hline RUA & TRECHO & Vazamentos \\
\hline MUN ANTONIO F. OZANAM & 1 & 5 \\
\hline MUN ANTONIO F. OZANAM & 2 & 2 \\
\hline A-JD SANTA HERMÍNIA & 3 & 2 \\
\hline A-JD SANTA HERMÍNIA & 4 & 1 \\
\hline A-JD SANTA HERMÍNIA & 5 & 3 \\
\hline C-JD SANTA HERMÍNIA & 6 & 2 \\
\hline DELTA-JD SANTA HERMÍNIA & 7 & 1 \\
\hline F-JD SANTA HERMÍNIA & 8 & 1 \\
\hline J-JD SANTA HERMÍNIA & 9 & 1 \\
\hline N-JD SANTA HERMÍNIA & 10 & 1 \\
\hline UM DA ES MUN BAIRRINHO & 11 & 1 \\
\hline
\end{tabular}

Com os dados coletados da rede de São José dos Campos, foi possível calcular as tensões de solo e tráfego; tensão da temperatura, tensão da pressão interna da tubulação, a tensão de flexão, tensão devido aos fenômenos transitórios, tensão devido a fadiga e tensão circunferencial final de cada trecho da tabela 1. A tabela 2 mostra as tensões calculadas para cada trecho.

Tabela 2. Trechos e suas respectivas tensões

\begin{tabular}{|c|c|c|c|c|c|c|c|}
\hline Trecho & $\mathbf{W}$ (MPa) & Temperatura (MPa) & Pi (MPa) & $\mathbf{f}(\mathbf{M P a})$ & TH (MPa) & FADIGA (MPa) & Tensão circunferencial \\
\hline 1 & 0,84 & 15,81 & 0,32 & 0,41 & 0,02 & 0,04 & 17,45 \\
\hline 2 & 5,06 & 3,49 & 1,62 & 10,45 & 0,11 & 0,05 & 20,78 \\
\hline 3 & 5,06 & 3,49 & 0,19 & 10,45 & 0,01 & 0,00 & 19,20 \\
\hline 4 & 5,06 & 3,49 & 4,24 & 10,45 & 0,28 & 0,00 & 23,51 \\
\hline 5 & 6,72 & 2,42 & 0,06 & 3,10 & 0,00 & 0,16 & 12,47 \\
\hline 6 & 5,06 & 3,49 & 0,67 & 10,45 & 0,04 & 0,03 & 19,74 \\
\hline 7 & 0,45 & 15,18 & 0,01 & 0,05 & 0,00 & 0,00 & 15,70 \\
\hline 8 & 5,06 & 3,49 & 2,17 & 10,45 & 0,14 & 0,09 & 21,40 \\
\hline 9 & 5,06 & 3,49 & 0,82 & 10,45 & 0,05 & 0,00 & 19,87 \\
\hline 10 & 0,84 & 15,81 & 0,03 & 0,41 & 0,00 & 0,00 & 17,10 \\
\hline 11 & 6,72 & 2,42 & 0,13 & 3,10 & 0,01 & 0,00 & 12,37 \\
\hline \multicolumn{7}{|c|}{ Conclus Ones } \\
\hline
\end{tabular}

Este trabalho realizou a análise reversa de um modelo de previsão de rupturas em redes de abastecimento de água confrontando os dados reais e teóricos. Verifica-se a dificuldade em estabelecer com precisão a previsão da falha, dadas as incertezas com relação aos dados operacionais. Além disso, há uma grande variabilidade por toda a rede de distribuição.

Apesar disso, este projeto auxiliará os gestores dos sistemas de gestão de redes de abastecimento de água nas tomadas de decisões.

KURITA, R. Y., DALFRÉ, J.G. , -Modelo para previsão de manutenção em sistemas de distribuição de água. Relatorio PIBIC - Unicamp, Campinas, 2008 KURITA, R. Y., DALFRÉ, J.G. , - Calibração de um modelo para previsão de manutenção em sistemas de distribuição de água. Relatório PIBIC -Unicamp, Campinas, 2009.

SOTERO, A. L. - Análise reversa de um modelo de previsão de manutenção em redes de abastecimento de água. - Tese de doutorado UNICAMP, 2011

ZANGENEHMADAR, Z. ; MOSELHI, O. - Deterioration factors of water pipelines using Delphi method, Measurement, Vol 90 (páginas 491-499), 2016.

FARMANI, R. ; KAKOUDAKIS, K. ; BEHZADIAN, K. ; BUTLER, D. - Pipe Failure Prediction in Water Distribution Systems Considering Static and Dynamic Factors Procedia Engineering, 2017 